\title{
Cadmium Ion Sensing Paptode Based On Digital RGB Color Analysis
}

\author{
Ruchi Dubey Sharma ${ }^{1}$, Sulbha Amlathe ${ }^{2 *}$ \\ ${ }^{1}$ Research Scholar, Department of Chemistry, BUIT, BU, Bhopal, MP, India. \\ ${ }^{2 *}$ Supervisor and HOD, Department of Chemistry, BUIT, BU, Bhopal, MP, India.
}

\begin{abstract}
A new optical analytical method, “digital RGB Analysis" is proposed based on MATLAB image processing tool instead of the conventional optical method, "spectrophotometry". MATLAB image processing tool can transform the color information into digital $R G B$ values that can be treated as analytical information. Image processing tool can simulate the optimum color variations by optimization of visual color sensor with computer assistance and thus make colorimetry (semi quantitative analysis) as an accurate determination method. The optode was constructed by immobilizing ninhydrin on TLC (thin layer chromatographic) paper. The reaction is based on complexation of ninhydrin with cadmium to result into a light purple to magenta colored spot followed by scanner based detection. Changes in $\boldsymbol{R G B}$ values of color spots on TLCstrips create a pattern. The obtained pattern was analyzed using image processing tool of MATLAB software to determine cadmium. All parameters affecting intensity on optode have been optimized. The proposed sensor was linear in the range 0.018-0.54 $\mu \mathrm{g} \mathrm{mL}^{-1}\left(R^{2}=0.996\right)$ for $G$ values and can sense up to $3 \mathrm{ng} \mathrm{mL}^{-1}$.SEM investigation of dye has also been done.The proportionality in intensity of the spot color on the optodes loaded with varying amounts of cadmium suggests its potential applications for determination of it in various samples. The paper optode can be used for pollutant check and even health check at home. Thus the paper optode has great potential for this purpose.
\end{abstract}

Keywords:MATLAB, nano dye particle paptode, RGB, thin layer chromatographic paper .

\section{Introduction}

Cadmium is one of the heavy metals more critical for the human health ${ }^{[1]}$. It enters the organism primarily via the alimentary and/or respiratory tract. It can be cause of diseases as: hypertension, arteriosclerosis, cancer, etc. Considering it, health organizations have established permissible limits for cadmium in food, including drinking water. TheWorld Health Organization (WHO) established as $3 \mu \mathrm{gL}^{-1}$ the maximum permissible for this element in drinking water. The limit established by Environmental Protection Agency (EPA) is $5 \mu \mathrm{gL}^{-1[2.3]}$.

The most human cadmium exposure comes from the tobacco smoke and from ingestion of foodwhich most of that arises from the uptake of cadmium by plants from fertilizers, sewage sludge, manure and atmospheric deposition ${ }^{[1,4]}$. More recently, the possible role of cadmium in human carcinogenesis has been also studied $^{[4,5]}$

Nowadays, cadmium is of interest as a toxic environmental pollutant since it has many adverse effects on humans, plants and animals. The need to monitor cadmium contamination in the environment at ever decreasing concentrations provides a driving force for the development of methods that are accurate and have low limits of detection, but are also simple, rapid, and inexpensive. Spot test analysis has been extensively studied for qualitative determination of materials on an absorbent material ${ }^{[6]}$. Reflectance spectroscopy cannot yield precision better than $10 \%$ when used to obtain quantitative data directly from spot test analysis ${ }^{[7]}$. Therefore, the results obtained from spot test analysis were considered unreliable but use of MATLABsoftware in the present method resulted into quantitative and reproducible spot test analysis.

Test strips for semi quantitative determination has been reported by Amlathe et $\mathrm{al}^{[8]}$. DCA Analysis for lithium has also been reported ${ }^{[9]}$. Paptodes for quantitative determination of various metal ions $\mathrm{As}, \mathrm{Fe}, \mathrm{Hg}, \mathrm{Zn}$ and Se have been reported ${ }^{[10-16]}$. The paptode is simply a paper or other ordinary porous material such as clay or cotton or Whatman filter paper or ordinary filter paper or even TLC can be used as a substrate support for reagent. A thorough description of RGB analysis has been described by Amlathe and co- workers ${ }^{[10]}$.

The usual methods for determination of cadmium involve Electrothermal atomization, GFAAS, Electrothermal Atomic Absorption spectrometry, Extraction spectrophotometry, Kinetic spectrophotometry, pulse polarography, spectrophotometry, Zeeman background correction, ICPMS, radiochemical neutron activation analysisetc. ${ }^{[17-26]}$. These methods are not compatible in terms of simplicity and economy. Colorimetry is the most appropriate choice due to its visible signal transduction in the presence of target. Besides, the reagents for colorimetry are most probable to be commercialized represented as pH paper, mercoquant, EMquant, ELISA, Quantafix etc. 
In the proposed method, we have described the use of paptode for analysis of cadmium. In the proposed sensor $1 \%$ ninhydrin solution was immobilized on TLC strips followed by drying. After injection of cadmium sample, a light purple to magenta colored spot of product (ninhydrin cadmium complex) was formed on the paptode. Blank also produces a light blue coloration in similar conditions that apparently seems similar to the color produced by lower concentration of cadmium but RGB values are much different. After drying of the spot, an image of each strip was recorded using a scanner. The color values of the spots were analyzed with MATLAB.

\section{Experimental}

2.1 Apparatus and software:JEOL JSM -6390 A SEM Made in Japan, JEOL JFC-1600 Sputter Coater unit.

The scanner (HP-SCANJET G2410). Resolution of scanner was regulated at 300 dpi. For analyzing color values in RGB (red, green, blue) system, the MATLAB software, which was written in Visual Basic 6 Media, was used.

A MICROLITE micro pipette was used for injecting samples on strips.

2.2 Chemicals and Reagents:All reagents used were analytical grade chemicals. Double distilled water is used throughout the experiment.

Cadmium stock-A stock of $1000 \mu \mathrm{g} \mathrm{mL}^{-1}$ was prepared by dissolving $163.07 \mathrm{mg}$ of $\mathrm{CdCl}_{2}$ in $100 \mathrm{ml}$ of double distilled water.

Ninhydrin $-1 \%$ ninhydrin solution was prepared by dissolving $1 \mathrm{~g}$ ninhydrin in acetone and then making up to $100 \mathrm{ml}$ by double distilled water.

\section{Procedure}

In presence of cadmium a light purple to magenta colored (depending upon the concentration) spot is produced on the sensors. To construct the sensor strips for cadmium, strips of TLC paper were immersed in $1 \%$ solution of ninhydrin for few seconds and then dried in a temperature controlled oven (to speed up drying). Aliquots of $18 \mu \mathrm{L}$ of cadmium solutions were injected on these strips and then strips are heated at $60-70^{\circ} \mathrm{C}$ in an oven for 15 minute to develop the spot. The strips were scanned and R, G and B values of spots were recorded by MATLAB after development of spot. The RGB color model is an additive color model in which red, green and blue light are added in various ways to produce a broad array of colors. Any color can be analyzed to obtain its corresponding R, G and B value. Effective intensity for any color values of color spots was calculated by following formulae:

$A_{\mathbf{r}}=-\log \left(\mathbf{R}_{\mathbf{s}} / \mathbf{R}_{\mathbf{b}}\right)$

$A_{g}=-\log \left(G_{\mathrm{g}} / \mathbf{G}_{\mathrm{b}}\right)$

$A_{b}=-\log \left(B_{s} / B_{b}\right)$

Where, $A_{r}, A_{g}, A_{b}$ are effective intensities of red, green and blue color respectively , $R_{s}, G_{s}, B_{s}$ and $R_{b}, G_{b}, B_{b}$ refer to $R, G$ and $B$ values of sample and blank respectively. The calibration curve is obtained by plotting effective intensities of $\mathrm{R}, \mathrm{G}$ and $\mathrm{B}$ values vs. analyte concentration.

\subsection{Chemical Reaction}

\section{Results And Discussion}

Ninhydrin forms a complex structure with cadmium to give the probable structure analogous to divalent metal complex with Schiff's base [27] when two ninhydrin molecules get co- ordinated with cadmium. Absence of acid formation is co-checked by phenolphthalein and methyl orange.
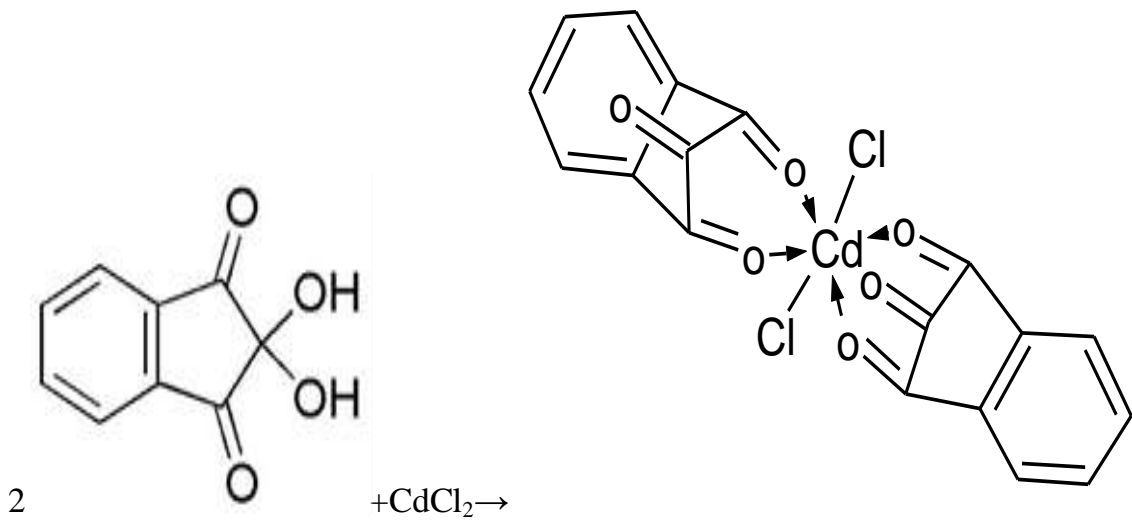

$+2 \mathrm{H}_{2} \mathrm{O}$ 

SAMPLE

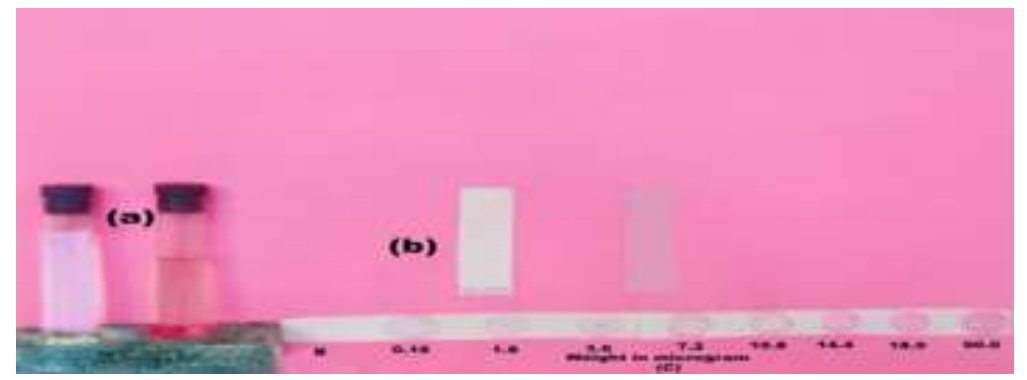

Where; (a) - Color development in solution; (b) - Color development on strip and (c)-Color variation on strip for different concentrations of cadmium

\subsection{SEM Investigation}

The dye has also been examined using scanning electron microscope (SEM) after gold coating. In SEM images dye appears a flower like structure with needles and petals. The size of petals and diameter of needles may be expected in nano meter as the images reveal.

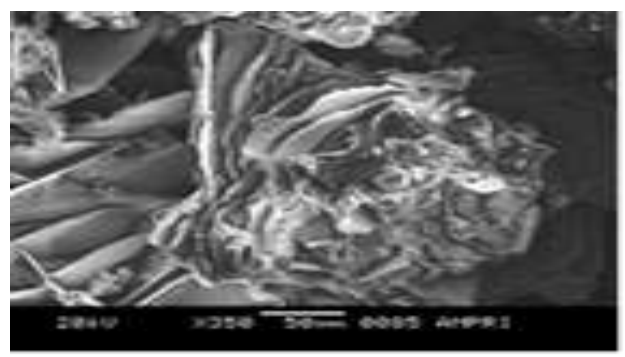

\section{MICROGRAPH}

4.3Optimization of conditions:

Injection volume:The influence of volume of analyte which must be injected onto strip was investigated. The optimum sample volume was obtained to be $18 \mu \mathrm{L}$.Increased volume injection leads to more diffusion of spots and thus consequently decreases the intensity of color.

Effect of reagent concentration:In order to study the effect of ninhydrin concentration, solutions with various concentrations of reagent was prepared and immobilized on TLC paper strips and then allowed to dry. After drying $18 \mu \mathrm{L}$ of a standard solution containing $40 \mu \mathrm{g} \mathrm{mL} \mathbf{L}^{-1}$ of cadmium was injected on each strip. After heating for 15 minute at $60-70^{\circ} \mathrm{C}$, the strips were scanned and their colors were analyzed by the software, and the effective intensities of $\mathrm{R}, \mathrm{G}$ and $\mathrm{B}$ values were plotted vs. concentration of ninhydrin. Figure 1 show the effect of ninhydrin concentration on spot intensities. At $1 \%$ concentration of ninhydrin maximum color intensity was observed and henceselected as optimum (figure 1).

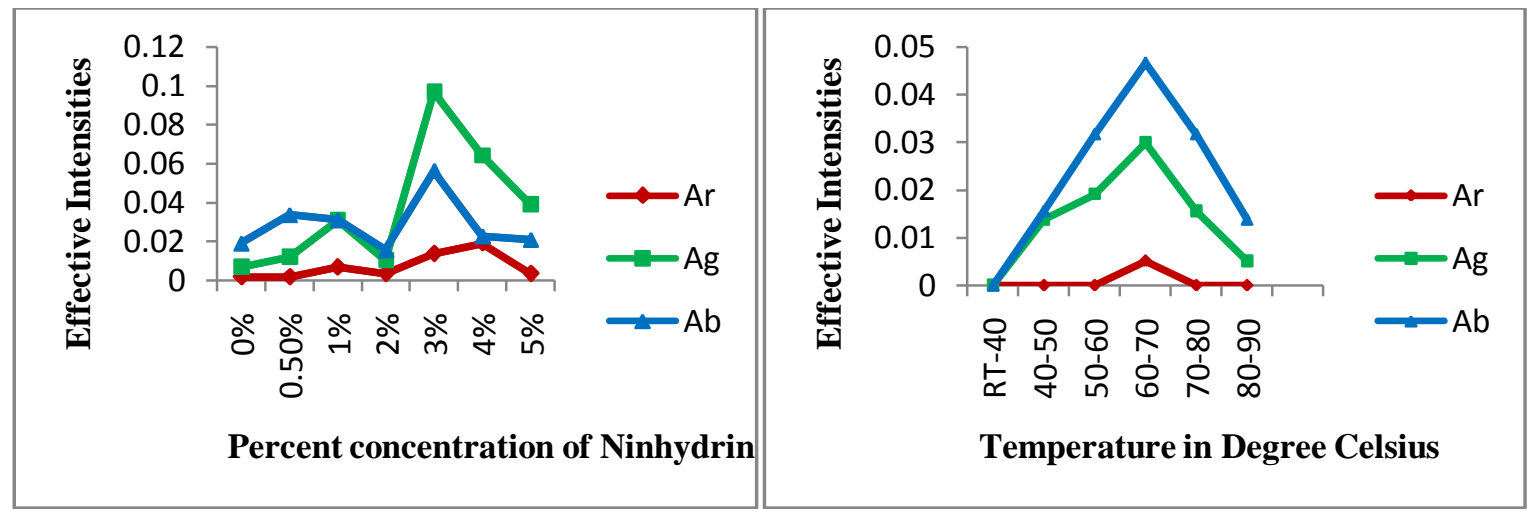

Fig.: 1 Effect of ninhydrin concentration Fig.: 2: Effect of Temperature

4.3.1 Drying Methods:Different methods of drying such as drying at room temperature, oven and hot air were used for drying the strips after injection of reagent onto strips but no considerable change in signals was observed. However, an oven is recommended for increasing the rate of drying. 
4.3.2 Effect of Temperature:The effect of temperature has been studied from room temperature to $90^{\circ} \mathrm{C}$ after

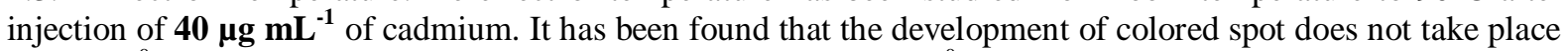
below $40^{\circ} \mathrm{C}$. The intensity was found to be increased from $40-70^{\circ} \mathrm{C}$ and then observed to be decreased. The maximum colored intensity was found between temperatures $60-70^{\circ} \mathrm{C}$ and hence selected as optimum for analysis(figure 2).

4.3.3 Response Time:The response time of the system was evaluated under optimum conditions for $\mathbf{4 0 \mu g} \mathbf{~ m L} \mathbf{L}^{-\mathbf{1}}$. It is the time required to achieve maximum color intensity. In the proposed method spot of maximum color intensity develops after 15 minute.

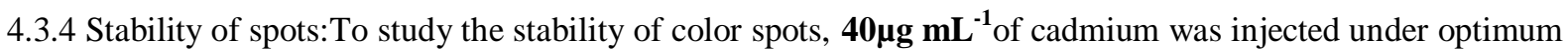
conditions on the sensor. Scanning of the sensor was done in the time period of 15, 30, 60,120, 180 and 240 minute and then after $24 \mathrm{hr}$ and $48 \mathrm{hr}$. The developed spot remain stable for more than two days.

4.3.5 Stability of sensor:To study the stability of sensor, after immobilizing reagent on the Whatman paper strip, it was used periodically each day. No significant change was observed within 20 days, afterwards spot lesser intensity develops. After $30^{\text {th }}$ day spot of a very poor intensity develops with a response time of more than 30 minute. Therefore, the prepared sensor can be used at best for 20 days and on a stretch for one month. The sensors were stored in dark to avoid any possibility of environmental oxidation of ninhydrin.

4.3.6 Detection Limit (DL):The practical DL is the lowest concentration, which gives color on strip no matter falls inlinearity range or not. For each RGB factor there is one $\mathrm{DL}^{[11]}$. Theoretical $\mathrm{DL}_{\mathrm{s}}$ of the method were $0.18 \mu \mathrm{g} \mathrm{mL}^{-1}$ for $\mathrm{R}, \mathrm{B}$ and 0.018 for $\mathrm{G}$ values respectively. Allthree values can be considered but $\mathrm{G}$ values are more sensitive and follow the standard linearity pattern as shown in figure 3 by trend line therefore, values are recommended for determination. Practical DL determined was $3 \mathrm{ng} \mathrm{mL}^{-1}$.

4.3.7 Calibration Curves: For obtaining calibration curve the effective intensities of spot were plotted against 1$100 \mu \mathrm{g} \mathrm{mL}^{-1}$ of cadmium for all three values ( $\mathrm{R}, \mathrm{G}$ and B). The increase in effective intensity with increasing concentration has been observed but the standard linearity pattern has been found in between the different concentrations. Change in linearity pattern occur due to change in shade of color and hence RGB pattern. In figure S1(Supplementary information) calibration curves for $0.5-40 \mu \mathrm{g} \mathrm{mL}{ }^{-1}$ of cadmium has been shown. From figure S2 (Supplementary information), it is clear that rather $\mathrm{G}$ values are higher but linearity co-efficient $\left(\mathrm{R}^{2}=0.99\right)$ is higher for $\mathrm{R}$ values.Figure 3show the higher $\mathrm{G}$ values as well as higher linearity co-efficient $\left(\mathrm{R}^{2}=0.996\right)$. Therefore, both $\mathrm{R}$ and $\mathrm{G}$ values can be equally considered but $\mathrm{G}$ values are recommended for their high sensitivity and reproducibility.

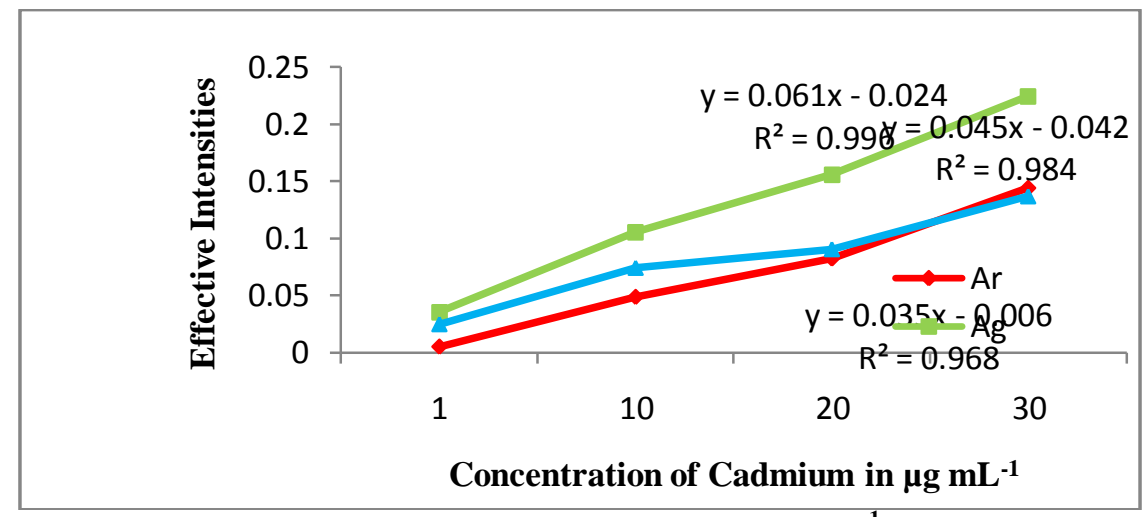

Fig.: 3Calibration curve for $1-30 \mu \mathrm{gL}^{-1}$

Reproducibility of the system:Reproducibility of sensor has been investigated at seven different sensors under optimum conditions for various concentrations of cadmium. The results are reported in table 1 and conclude that the proposed method is reproducible. 
Cadmium ion Sensing Paptode Based on Digital RGB Color Analysis

Table: 1 Average, SD (standard deviation) and RSD (relative standard deviation) of seven repetitive analyses

\begin{tabular}{|c|c|c|c|c|c|c|c|c|c|c|}
\hline $\begin{array}{l}\text { S. } \\
\text { No. }\end{array}$ & $\begin{array}{l}\mu_{1} \mathrm{gLL}^{-} \\
1_{\text {of }} \\
\text { cadmium } \\
\text { solution }\end{array}$ & $\begin{array}{l}\text { A }_{\mathbf{r}} \\
\text { Avg. } \\
\text { RSD\% }\end{array}$ & SD & & $\begin{array}{l}A_{g} \\
\text { Avg. }\end{array}$ & SD & SD\% & $\begin{array}{l}A_{b} \\
\text { Avg. } \\
\text { RSD\% }\end{array}$ & SD & \\
\hline 1. & 1 & 0.0053 & 0.003 & 56.6 & 0.035 & 0.0012 & 2.85 & 0.0253 & 0.0016 & 6.65 \\
\hline 2. & 20 & 0.0837 & $\mathbf{0 . 0 0 3 5}$ & 4.17 & 0.1553 & 0.0015 & 1.01 & 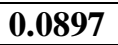 & 0.0021 & 2.40 \\
\hline 3. & 40 & 0.1767 & 0.0051 & 2.88 & $\mathbf{0 . 2 3 9 5}$ & 0.003 & 1.25 & 0.1581 & $\overline{0.0035}$ & 2.21 \\
\hline
\end{tabular}

4.3.8 Interference studies:To study the selectivity of the proposed method, the effect of various species on the determination of $\mathbf{4 0 \mu \mathbf { g ~ m L }} \mathbf{~ L}^{-1}$ of cadmium was tested under optimum conditions without any masking. The tolerance limit was defined as the concentration of the added species that causes $\pm 5 \%$ relative error. Results reveal that except $\mathrm{Al}^{3+}$ there is no interference offered by other metal ions (Table 2).

Table: 2: Tolerance limit of various interfering species on determination of cadmium

\begin{tabular}{|l|l|l|}
\hline S.No. & Interfering species & Tolerance limit $\left(\mathrm{mgL}^{-1}\right)$ \\
\hline 1 & $\mathrm{Mn}^{2+}, \mathrm{Na}^{+}, \mathrm{HCO}_{3}{ }^{2-}$ & 200 \\
\hline 2 & $\mathrm{~K}^{+}, \mathrm{Cr}^{3+}, \mathrm{NH}_{3}$ & $\mathbf{1 0 0 0}$ \\
\hline 3 & $\mathrm{As}^{3+}$ & 400 \\
\hline 4 & $\mathrm{Se}^{3+}$, & 250 \\
\hline 5 & $\mathrm{Fe}^{2+}, \mathrm{NH}_{4}{ }^{+}, \mathrm{SO}_{4}{ }^{2-}, \mathrm{Ba}^{2+}, \mathrm{Cl}^{-}, \mathrm{Zn}^{2+}$ & 5000 \\
\hline 6 & $\mathrm{Cu}^{2+}, \mathrm{Ca}^{2+}$ & 250 \\
\hline 7 & $\mathrm{Al}^{3+}$ & $\mathbf{8 0}$ \\
\hline 8 & $\mathrm{Hg}^{2+}, \mathrm{Pb}^{+}$ & $\mathbf{5 0 0}$ \\
\hline
\end{tabular}

5.1 In Analysis of real samples:

\section{Application Of Disposable Sensors}

Theproposed sensor has been successfully applied for determination of cadmium in various samples by developed as well as reported method ${ }^{[25]}$. Using the calibration curve, the concentration of cadmium in rice, wheat, tap water, effluent water and urine samples were calculated. The results are given in Table 3 . The results reveal that cadmium can be determined quantitatively in the region assessed.

Table: 3: Percent recovery of cadmium in environmental samples.

\begin{tabular}{|c|c|c|c|c|c|c|}
\hline $\begin{array}{l}\text { S. } \\
\text { No } \\
\text {. }\end{array}$ & Sample & $\begin{array}{l}\text { Cadmium } \\
\text { originally found }\end{array}$ & $\begin{array}{l}\text { Cadmium } \\
\text { added }\end{array}$ & $\begin{array}{l}\text { Total } \\
\text { cadmium } \\
\text { found }\end{array}$ & $\begin{array}{l}\% \text { recovery } \\
\text { by } \\
\text { developed } \\
\text { method }\end{array}$ & $\begin{array}{l}\% \text { recovery } \\
\text { by reported } \\
\text { method }\end{array}$ \\
\hline 1 & $\begin{array}{c}\text { Effluent Water } 1 \\
\mathbf{2} \\
\mathbf{3} \\
\end{array}$ & $\begin{array}{l}1.0 \mu \mathrm{g} \\
0.8 \mu \mathrm{g} \\
0.6 \mu \mathrm{g}\end{array}$ & $\begin{array}{l}10 \mu g \\
20 \mu g \\
30 \mu g\end{array}$ & $\begin{array}{c}10 \mu \mathrm{g} \\
20.0 \mu \mathrm{g} \\
30.5 \mu \mathrm{g}\end{array}$ & $\begin{array}{l}90.9 \\
96.1 \\
99.6\end{array}$ & $\begin{array}{l}90.6 \\
95.2 \\
98.6\end{array}$ \\
\hline 2 & $\begin{array}{rr}\text { Tap Water } & 1 \\
2 & \\
3 & \\
\end{array}$ & $\begin{array}{l}\text { Nil } \\
\text { Nil } \\
\text { Nil } \\
\end{array}$ & $\begin{array}{l}10 \mu \mathrm{g} \\
20 \mu \mathrm{g} \\
30 \mu \mathrm{g}\end{array}$ & $\begin{array}{c}10.0 \mu \mathrm{g} \\
19.5 \mu \mathrm{g} \\
28.5 \\
\end{array}$ & $\begin{array}{c}100.0 \\
97.5 \\
95.0 \\
\end{array}$ & $\begin{array}{l}99.9 \\
96.4 \\
94.0 \\
\end{array}$ \\
\hline 3 & $\begin{array}{ll}\text { Rice } & \\
& \mathbf{2} \\
& \mathbf{3} \\
\end{array}$ & $\begin{array}{l}2.0 \mu \mathrm{g} \\
1.0 \mu \mathrm{g} \\
2.0 \mu \mathrm{g} \\
\end{array}$ & $\begin{array}{l}10 \mu \mathrm{g} \\
20 \mu \mathrm{g} \\
30 \mu \mathrm{g} \\
\end{array}$ & $\begin{array}{l}12.0 \mu \mathrm{g} \\
20.5 \mu \mathrm{g} \\
32.0 \mu \mathrm{g} \\
\end{array}$ & $\begin{array}{c}100.0 \\
97.6 \\
100.0 \\
\end{array}$ & $\begin{array}{l}98.4 \\
95.2 \\
98.7 \\
\end{array}$ \\
\hline 4 & $\begin{array}{ll}\text { Wheat } & \\
& \mathbf{2} \\
& 3 \\
\end{array}$ & $\begin{array}{l}4.0 \mu \mathrm{g} \\
5.0 \mu \mathrm{g} \\
4.0 \mu \mathrm{g}\end{array}$ & $\begin{array}{l}10 \mu \mathrm{g} \\
20 \mu \mathrm{g} \\
30 \mu \mathrm{g}\end{array}$ & $\begin{array}{l}13.0 \mu \mathrm{g} \\
23.0 \mu \mathrm{g} \\
31.0 \mu \mathrm{g}\end{array}$ & $\begin{array}{l}92.8 \\
92.0 \\
91.1 \\
\end{array}$ & $\begin{array}{l}91.0 \\
91.2 \\
90.8 \\
\end{array}$ \\
\hline 5 & $\begin{array}{ll}\text { Urine } & \\
& \mathbf{2} \\
& \mathbf{3} \\
\end{array}$ & $\begin{array}{l}<0.5 \\
<0.5 \\
<0.5 \\
\end{array}$ & $\begin{array}{l}10 \mu \mathrm{g} \\
20 \mu \mathrm{g} \\
30 \mu \mathrm{g}\end{array}$ & $\begin{array}{l}11.0 \mu \mathrm{g} \\
20.5 \mu \mathrm{g} \\
30.0 \mu \mathrm{g}\end{array}$ & $\begin{array}{c}100.4 \\
\sim 100.0 \\
\sim 98.3 \\
\end{array}$ & \begin{tabular}{c|}
100.0 \\
99.6 \\
99.3 \\
\end{tabular} \\
\hline
\end{tabular}

\subsection{In Removal of Cadmium: As Filter}

Cadmiumposes a series risk to the environment and endangers public health. Presence of it in drinking water system is a potential health hazard. Therefore, they should be removed from water and wastewaters before discharge. Thus, there is a hunger need for a cost effective method for removal of cadmium from water. There are many methods available in literature for removal of heavy metals from aqueous samples ${ }^{[28-39]}$. However; 
complete elimination of heavy metals at very low concentrations through these is not possible; are expensive as these require advanced equipment and high energy.

The paptode based on RGB analysis was successfully applied for removal of cadmium from aqueous sample. Cadmium may be discharged to water through fertilizers,manure and sewage ${ }^{[1,4]}$. Real samples containing $\mathrm{Cd}$ were not available hence synthetic samples were prepared by adding a known amount of Cadmium to water.

The constructed paptode is used as filter for removal of cadmium. Cadmium sample containingdifferent concentration are allowed to be filtered through it in batches and the sensors were scanned before and after adsorption to know the change in RGB values. It is observed that with lower concentrations adsorption was more i.e.sensors become more effective (Figure: 5). Results of percent adsorption are reported in Table: 4.The disposable filter is allowed to remain in contact of $40 \mu \mathrm{g} \mathrm{mL} \mathrm{L}^{-1}$ cadmium solution for an hour and change in B value is observed at every 15 minute. It is found that best adsorption took place within 15 minute.

\begin{tabular}{|c|c|c|c|}
\hline S. No. & $\begin{array}{l}\text { Concentration of } \\
\text { cadmium before } \\
\left.\text { removal }(\mu \mathrm{g} \mathrm{mL})^{-1}\right)\end{array}$ & $\begin{array}{lr}\begin{array}{l}\text { Concentration } \\
\text { cadmium } \\
\text { removal }\left(\mu \mathrm{g} \mathrm{mL} \mathrm{L}^{-1}\right)\end{array} \\
\end{array}$ & Percent removal \\
\hline 1 & 1000 & 150 & 85.0 \\
\hline 2 & 500 & 40 & 92.0 \\
\hline 3 & 250 & 15 & 94.0 \\
\hline 4 & 100 & 0.5 & 95.5 \\
\hline
\end{tabular}

Table: 4: Percent Removal of cadmium

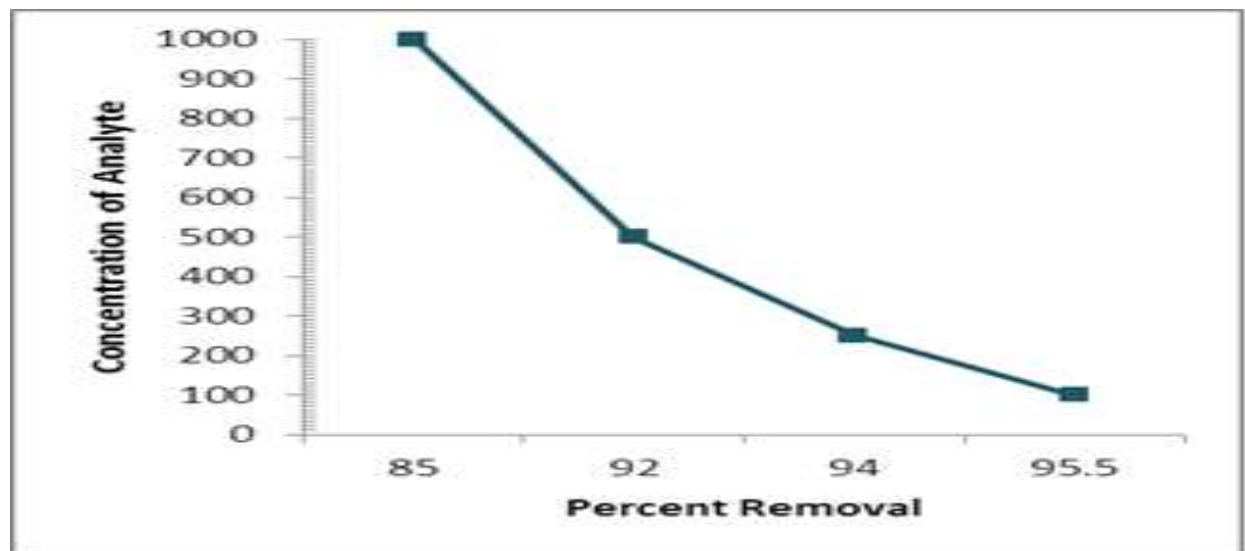

Fig.: 5:Percent Removal of Analyte

VI. Conclusions

The proposed method is found to be superior and produces quantitative results for determination over existing methods. The method described isadvantageous being non instrumental, simple and rapid, wider linear range, application do not require any skilled labor or operation (Table 5). The method is also applicable for effective removal of cadmium. The shorter response time, portability, ease of reagent immobilization, instantaneity to adsorb and remove cadmium are considerable advantages of developed paptode. The paptodehas been successfully used for testing and removing cadmium on the spot in various food and biological samples.

Table: 5 Comparison of proposed method with other methods

\begin{tabular}{|c|c|c|c|c|c|}
\hline $\begin{array}{c}\text { S. } \\
\text { No. }\end{array}$ & Reagents & Method & $\begin{array}{c}\text { Range of } \\
\text { Determinatio } \\
\text { n }\end{array}$ & $\begin{array}{c}\text { Detectio } \\
\text { n Limit }\end{array}$ & Remarks \\
\hline 1 & TritonX-100, $\mathrm{HNO}_{3}{ }^{[17]}$ & $\begin{array}{c}\text { Electrothermal } \\
\text { Atomization }\end{array}$ & $\begin{array}{c}\mathbf{0 . 0 5 - 3 . 0 n g} \\
\mathbf{m L}^{-1}\end{array}$ & NA & $\begin{array}{c}\text { High Skilled } \\
\text { operation is } \\
\text { required, } \\
\text { expensive, } \\
\text { Very low } \\
\text { volume is } \\
\text { required. }\end{array}$ \\
\hline 2 & Di thiozone, Naphthalene ${ }^{[18]}$ & GFAAS & - & 1.2 L L $^{-1}$ & $\begin{array}{c}\text { Complicate } \\
\text { d, expensive }\end{array}$ \\
\hline 3 & Arsenazo I, Hydrogen & Kinetic & $\mathbf{0 . 0 0 2 - 0 . 2 5 ~ \mu g}$ & NA & Non \\
\hline
\end{tabular}


Cadmium ion Sensing Paptode Based on Digital RGB Color Analysis

\begin{tabular}{|c|c|c|c|c|c|}
\hline & peroxide $^{[21]}$ & $\begin{array}{c}\text { spectrophotometr } \\
\mathbf{y}\end{array}$ & 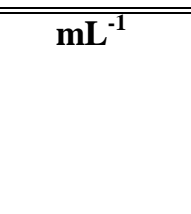 & & $\begin{array}{c}\text { selective, } \\
\mathrm{Mg}^{2+}, \mathrm{Ca}^{2+}, \\
\mathrm{Zn}^{2+} \text { and } \\
\mathrm{Sn}^{2+} \\
\text { interfere }\end{array}$ \\
\hline 4 & 1-(2-pyridilazo)-2-naphthol ${ }^{[22]}$ & $\begin{array}{c}\text { Pulse } \\
\text { polarography }\end{array}$ & $\begin{array}{l}\text { 0.1-150 } \mu \mathrm{g} \\
\mathrm{mL}^{-1}\end{array}$ & $\begin{array}{l}70.0 \mathrm{ng}^{7} \\
\mathrm{~mL}^{-1}\end{array}$ & $\begin{array}{c}\text { Less } \\
\text { sensitive, } \\
\text { Time } \\
\text { consuming }\end{array}$ \\
\hline 5 & $\begin{array}{l}\text { 2-Hydroxy- 4-n-butoxy-5- } \\
\text { bromopropiophenone } \\
\text { thiosemicarbazone } \\
\end{array}$ & $\begin{array}{l}\text { Spectrophotometr } \\
\mathbf{y}\end{array}$ & $\begin{array}{c}\text { 15.62-16.86 } \\
\mu \mathrm{g} \mathrm{mL-1}\end{array}$ & NA & $\begin{array}{c}\text { Less } \\
\text { sensitive, a } \\
\text { traditional } \\
\text { method }\end{array}$ \\
\hline 6 & $\begin{array}{c}0- \\
\text { Carboxybenzenediazoaminob } \\
\text { enzene-p-azo Benzene }{ }^{[24]}\end{array}$ & $\begin{array}{l}\text { Spectrophotometr } \\
y\end{array}$ & $\begin{array}{l}0.1-0.9 \mu g \\
m^{-1}\end{array}$ & NA & $\begin{array}{c}\text { pH } \\
\text { dependent }\end{array}$ \\
\hline 7 & Ninhydrin (present method) & $\begin{array}{c}\text { MATLAB } \\
\text { assisted RGB } \\
\text { analysis }\end{array}$ & $\begin{array}{c}\text { 0.018-0.54 } \\
\mu \mathrm{g} \mathrm{mL} \mathrm{L}^{-1}\end{array}$ & $\begin{array}{c}3 \\
\mathrm{ng} \mathrm{\textrm {mL } ^ { - 1 }}\end{array}$ & $\begin{array}{c}\text { Highly } \\
\text { sensitive, } \\
\text { Quantitative } \\
\text {, Rapid, } \\
\text { removal is } \\
\text { possible }\end{array}$ \\
\hline
\end{tabular}

\section{Acknowledgement}

The authors are grateful to Director MPCST Bhopal for providing financial assistance,R D Sharma is grateful to MPCST, Bhopal for awarding JRF on project, Director AMPRI, Principal, Govt. Sarojini Naidu Girls College Bhopal and Director, BUIT Barkatullah University Bhopal for providing lab facilities.

\section{Reference}

[1] A.C. Davis, P. Wu, X.F. Zhang, X.D. Hou, B.T. Jones, Determination of cadmium in biological samples, Appl. Spectrosc. Rev.2006, 41 (1) $35-75$.

[2] World Health Organization (WHO), Guidelines for DrinkingWater Quality, Health Criteria and Other Supporting Information,2011, $2,3^{\text {rd }}$ ed., Geneva.

[3] Environmental Protection Agency (EPA), EPA 822-R-02-38, Washington, DC, 2002, http://www.epa.gov/waterscience/drinking/standards.html.

[4] N.N. Greenwood, A. Earnshaw, Chemistry of the Elements (Pergamon Press, Oxford, 1989).

[5] J.H. Mennear, Cadmium Toxicity (Dekker, New York 1979).

[6] F. Feigl and V. Anger, Spot test in inorganic analysis(first Indian reprint, $6^{\text {th }}$ edElsevier, Amsterdam, 2005).

[7] D. Kealey, Quantitative reflectometry-I: Principles and scope,Talanta, 1972, 19,1563.

[8] S. Amlathe and V. K. Gupta,A Sensitive Spectrophotometric Determination of Traces of Pyridine with Anthralic Acid in Environmental samples, Microchemical journal, 1990, 42,331-335.

[9] E.Hirayama, T Sugiyama,H.Hisamoto and K.Suzuki,Visual and Colorimetric Lithium Ion Sensing Based on Digital Color Analysis, Anal. Chem. 2000, 72,465-474.

[10] R. D. Sharma, S. Joshi and S. Amlathe, MATLAB assisted disposable sensors for quantitative determination of arsenic, Anal. Methods, 2011, 3(2),452-456.

[11] A. Abbaspour, M. A. Mehrgardi, A. Noori, M.A. Kamyabi, A.Khalafi-Nezhad and M. N. Soltani Rad, Speciation of iron(II), iron(III) and full-range $\mathrm{pH}$ monitoring using paptode: A simple colorimetric method as an appropriate alternative for optodes, Sensors and Actuators B, 2006, 113,857-862.

[12] H Tavallali\&ENike, A Simple and Selective Sensor for Determination of Iron (II) in drug samples based on Paptode, Asian Journal of Biochemical and Pharmaceutical Research, 2011, 1(3), 91-97.

[13] A.A.Ensafi and M.Fouladgar,Development of a Spectrophotometric Optode for the Determination of Hg (II),IEEE Sensors Journal,2008, 8(4),347-351.

[14] Y. Kalyan, A. K. Pandey, P. R. Bhagat, R. Acharya, V. Natarajan, G. R. K. Naidu, A. V. R. Reddy, Membrane optode for mercury(II) determination in aqueous samples, Journal of Hazardous Materials, 2009,166 (1),377-381.

[15] R. D. Sharma and S Amlathe, Quantitative determination and removal of zinc using disposable colorimetric sensors: An appropriate alternative to optodes, Journal of Chemical and Pharmaceutical Research, 2012,4(2),1097-1105.

[16] R. D.Sharma and S Amlathe, Disposable Chemo Sensor for Quantitative Determination and Removal of Selenium, International Journal of Research in Chemistry and Environment,2012, 2 (2), 87-95.

[17] M. Hoenig, The Direct Determination of Cadmium in Blood by Electrothermal Atomization with the Graphite Platform, Application Note, Atomic Absorption, AgilentTechnologies@www.agilent.com/chem, $\odot$ Agilent Technologies, Inc., 1985, USA, November 1, 2010, AA049.

[18] A.Nezhadali and S Nazari, Graphite Furnace Atomic Absorption Spectrometric Determination of Cadmium after Solid-Liquid Extraction with Dithiozone, Bull. Chem. Soc. Ethiop.2009, 23(2), 257-261.

[19] W Chuachuad and J F Tyson, , Determination of Cadmium by Electrothermal Atomic Absorption Spectrometry with Flow Injection Chemical Vapor Generation from a Tetrahydroborate-form Anion-exchanger and In-atomizer Trapping, Canadian Journal ofAnalytical Sciences and Spectroscopy,2004, 49 (6), 362-373.

[20] B. Jankiewicz, B. Ptaszyński, M. Wieczorek, Spectrophotometric Determination of Cadmium (II) in Soil of Allotment Gardens in Łódź,Polish Journal of Environmental Studies, 2000, 9(2), 83-86. 
[21] L.Jusheng, T.Jiuying, W.Hong, L.Guangchao, Simultaneous kinetic spectrophotometric determination of trace cadmium and lead by inhibition of the arsenazo I - hydrogen peroxide reaction,Canadian Journal of Analytical Sciences and Spectroscopy, 2008, 53(5),214-219.

[22] Mohd.A.Taher, Differential Pulse Polarographic Determination of Cadmium After Solid Liquid Extraction and Preconcentration Using PAN,Turk J Chem, 2003, 27, 529 - 537.

[23] K. S. Parikh, R. M. Patel and K. N. Patel, New Spectrophotometric Method for Determination of Cadmium,E-Journal of Chemistry, 009, 6(S1), S496-S500, http://www.e-journals.net-sph.

[24] L.Cherian and V. K. Gupta, Spectrophotometric Determination of Cadmium with 0-Carboxybenzenediazoaminobenzene-p-azo Benzene, Microchemical Journal,1991, 43,198-203.

[25] M. Knowles, Methods for the Determination of Cadmium in Sea Water with Zeeman Background Correction, Application Note, ( $)$ Agilent Technologies, Inc., 1987, Printed in the USA, November 1, 2010, AA071, www.agilent.com/chem.

[26] D. Potter, The Determination of Cadmium, Lead and Mercury in Whole Blood by Inductively Coupled Plasma Mass Spectrometry, Application Note, 1-6, Clinical, (C) 2000, Agilent Technologies, Inc., Printed 4/2000, Publication number 5963-5489E, http:/www.agilent.com/chem/icpms.

[27] D. P. Singh and R. M. N.Chopra, Divalent Metal Complexeswith Ligand Derived fromNinhydrinandAromaticDiaminesandComparisonsoftheirReactivities,RasayanJournalof Chemistry, 1(1), 2008, 93-98.

[28] A.Promsawad, A.KongsakphaisalandS.Laoharojanaphand, Determination of Cadmium in Rice by Radiochemical Neutron Activation Analysis,KMITI Sci. J.,2008, 8(2B), 12-17.

[29] E. Erdem, N. Karapinar and R. Donat, The Removal of Heavy Metal Cations by Natural Zeolites, Journal of Colloid and Interface Science, 2004, 280, 309-314.

[30] J. S. Kim, J.C. Park and J. Yi, Zinc Ion Removal from Aqueous Solutions Using Modified Silica Impregnated with 2-Ethylhexyl 2EthylhexylPhosphonic Acid, Separation Science and Technology, 2000, 35(12), 1901-1916.

[31] E. Alvarez Ayuso, A. Garcia Sanchez, and X. Querol, Purification of Metal Electroplating Waste Water using Zeolites, Water research, 2003, 37, 4855-4862.

[32] E Alvarez Ayuso and A Garcia Sanchez, Removal of Metals from waste Waters by Natural and Na-Exchanged Bentonites, Clay and Clay Minerals, 2003, 51(5), 475-480.

[33] J. Rubio and S. Tessele, Removal of Heavy Metal Ions by Adsorptive Particulate Flotation, Minerals Engineering, 1997, 10(7), 671679.

[34] M. Malakootian, A. Almasi and H. Hussaini, $\mathrm{Pb}$ and Co Removal from paint industries effluent using Wood Ash,Int. Journal Env. Sci. and Tech.,2008, 5(2),217-222.

[35] M. Visa, Heavy Metals Removal on Dye modified Fly Ash Substrates, World of Coal Ash (WOCA) conference, Denver, CO, USA, 2011, 9-11 May.

[36] L. I. Fen Ting, L. I. Xia, B. R. Zhang and Q. H. Ouyang, Removal of Heavy Metals in Effluent by Adsorption and Coagulation, Chinese Chemical Letters, 2004, 15(1), 83-86.

[37] R. Ahmadi and A. Khodadadi, Heavy metal Removal from Waste Waters by an Ion Flotation, Soil Contamination, $15^{\text {th }}$ ICHMT, 761.

[38] H. Bedelean, A. Maicaneanu, M. Stanca and S. Burca, Removal of Heavy Metal ions from Waste Water using Natural Materials,StudiaUnivrsitatis Babes, Bolyai, Geolgia, , 2009, Special Issue, MAEGS, -16.

[39] A.M.Garciaand S.V.Gomez, A.E.Mansilla, Adsorption of mercury, cadmium and lead from aqueous solution on heat-treated and sulphurized activated carbon,Journal of Water Res.,1998, 32, 1-4. 